\title{
Getting it right: the roles of research, stakeholders, and delivery for a seasonal streamflow forecasting service across Australia
}

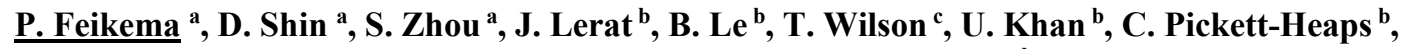 \\ A. MacDonald ${ }^{a}$, D. Kent ${ }^{a}$ and N.K. Tuteja ${ }^{b}$ \\ ${ }^{a}$ Environment and Research Division, Bureau of Meteorology, Victoria, Australia \\ ${ }^{b}$ Environment and Research Division, Bureau of Meteorology, Australian Capital Territory, Australia \\ ${ }^{c}$ Environment and Research Division, Bureau of Meteorology, Queensland, Australia \\ Email:p.feikema@bom.gov.au
}

\begin{abstract}
The Bureau of Meteorology (Bureau) provides an operational seasonal streamflow forecasting service that, each month, issues three month ahead forecasts of total water volumes at about 200 locations across Australia (http://www.bom.gov.au/water/ssf/). Development of this service began in 2009, it became operational in 2010, and continues to be user driven, because it must ultimately influence decision making that results in improvements to water resource management.
\end{abstract}

Service development has been led by the Extended Hydrological Prediction (EHP) section within the Bureau, and research and development support from the following partners has been critical. These partners include the Water Information Research and Development Alliance (WIRADA, a research collaboration between the Bureau and CSIRO), the Research and Development Branch within the Bureau, and the university sector. Modelling approaches developed through these collaborations form the basis of the service. Forecasts are provided to the public using a statistical modelling approach based on relationships derived directly from observed streamflow data and derived climate (predictor) indices. Forecasts based on rainfall-runoff modelling forced by downscaled rainfall forecasts (dynamic approach) are currently being released to and evaluated by registered users. This approach takes advantage of outputs from the Bureau's operational seasonal climate model. Current work is underway to combine forecasts from the statistical and dynamic approaches to provide merged forecasts that capture the strengths of each approach, thereby providing forecasts with greater accuracy and reliability.

Delivery, and continued development of the seasonal streamflow forecast service, requires attention to a wide variety of tasks. It requires cooperation with internal and external stakeholders, along with a comprehensive understanding of user needs, research and development support, robust operational modelling tools and webbased service delivery systems, a communication and adoption strategy and an implementation plan.

For example, the forecasting service relies on good quality historical and near real-time climate and hydrological data, especially streamflow. The service relies heavily on the Australian Water Resources Information System (AWRIS) for hydrological and related geospatial data, with the seasonal streamflow forecasting service being the first operational service utilising AWRIS. Assessing and controlling the quality of observed data used for forecasting is a core process that enhances forecast quality.

Current development of the service is focussed on site expansion, in order to provide forecasts to many more end users across Australia. Reaching these potential users has always been a challenge. In recent years, the Bureau has diversified its communication channels by organising regular briefings to key stakeholders (e.g. National and Climate Water Briefing) and by moving into social media, embracing Facebook, twitter, and YouTube, on top of its usual delivery channel - the standard Bureau web pages. This provides an avenue for water forecasts, in the context of climate information, to reach many more users in a clear way that is easily understandable, and that can ultimately enhance decision making.

This paper discusses evolution of the seasonal streamflow forecasting service in Australia, including some of the challenges faced, and examines how the many collaborative partnerships in areas of research, stakeholders and delivery, have enabled it to develop.

Keywords: Seasonal water availability prediction, hydrological modelling, water forecasting, seasonal streamflow forecasting 


\section{INTRODUCTION}

The Bureau of Meteorology (Bureau) has been providing seasonal streamflow forecasts since 2010 at http://www.bom.gov.au/water/ssf/ in its role to deliver timely, accurate and reliable water availability forecasts across Australia (Vertessy, 2013; Tuteja, 2015). A forecasting service such as this was driven by the need to provide water allocation outlooks, inform water markets, plan and manage water use and manage drought. This became even more urgent during the millennium drought between 1997 and 2009, and led to the announcement in May 2008 of the Water for the Future program, including the Improving Water Information Program administered by the Bureau and backed by the Water Act 2007 and key stakeholders.

One of the roles of the Bureau under the Water Act 2007 was to provide regular forecasts of future water availability of Australia's water resources. While the Bureau had been issuing routine flood forecasting services for immediate hazard for over 50 years, it was now required to provide estimates of water availability across a range of time frames.

Here, we describe steps taken along an interesting journey since 2009, and the vital roles that many different groups have played, in developing and providing Australia's national streamflow forecasting service (BoM, 2010). First, we describe the current operational service, and then look at the important ingredients that were required, and how the service plans to evolve in the future.

\section{CURRENT FORECASTING SERVICE}

The Bureau commenced providing a seasonal streamflow forecasting service to the public in December 2010. By the $7^{\text {th }}$ working day of the month, probabilistic forecasts of streamflow volumes over the next three months are issued for locations across Australia. These locations can either be at a gauging point along a river, or represent total flows into a water storage. The service currently provides forecasts at 140 locations to the public, and forecasts at 196 locations (including the 140 public locations) are provided to registered users through restricted access. The service provides a variety of forecast products (probabilities as an example shown in Fig. 1a), forecast verification and data products. These are all downloadable for each location, and supporting information is also available (e.g. FAQ, glossary, case studies). Other products, such as a map showing the most likely flow category (low, near median or high flow; Fig. 1b) are used to provide a national overview in the monthly email and in stakeholder briefings.
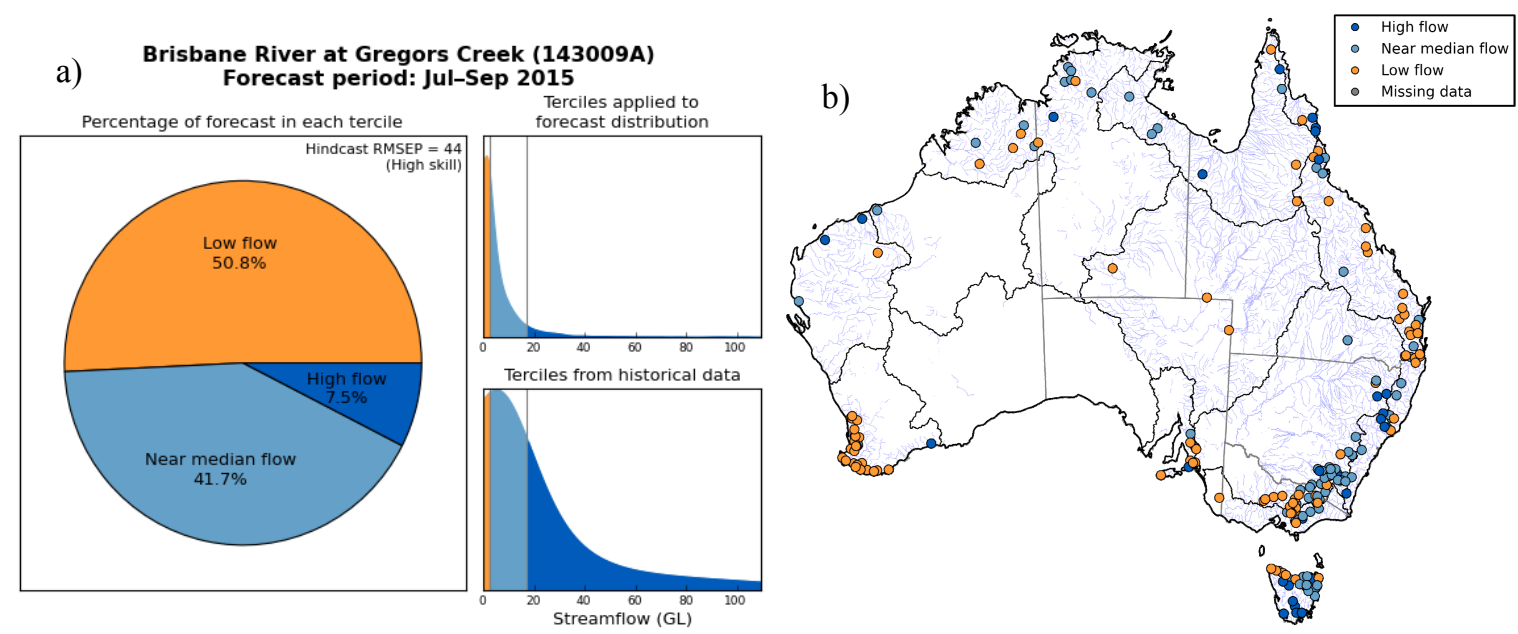

Figure 1a) Probabilistic forecast for the Brisbane River at Gregors Creek, with historical data for the period 1970-2008 for reference, and b) A forecast map of the most likely flow category at 196 locations.

The operational service is based on a statistical approach using a Bayesian Joint Probability (BJP) modelling method (Wang et al., 2009; Wang and Robertson, 2011). This method empirically captures relationships between streamflow volume in a forecast period (predictand) and the initial states of catchment and climate (predictors).

The service heavily relies on the availability of observations of streamflow for the previous month (see Fig. 2 ), and these must be available by the $4^{\text {th }}$ working day of the month in order for data checking and forecast generation to occur. Data checking to identify irregularities or missing data is an important, yet time consuming step, which has increased substantially as more locations are brought into the service. This process involves removal of spurious peaks and gap-filling of missing records with nearby interpolation, all 
triggered by a visual inspection of each time series. Once data checking is complete, forecast generation occurs, which then takes approximately 16 hours. Text for the web front page and monthly email is prepared to provide a summary of forecasts, and to place these in the context of recent climate and streamflow observations. Forecasts are released to the public by the $7^{\text {th }}$ working day of the month (Fig. 2).

In addition to the BJP statistical approach, forecasts are produced and made available to registered users only using a dynamic model. This model, called GR4J, (Perrin et al., 2003), captures predictability arising from future climate and antecedent catchment conditions. Eventually, forecasts from the statistical and dynamic approaches will be merged with the aim of improving forecast quality.

The Bureau's seasonal streamflow forecasting system, known as Water Availability Forecasts of Australian Rivers (WAFARi; Shin et al., 2011) provides the framework to produce forecasts based on statistical and dynamic approaches. Currently, $90 \%$ of processes required to issue the monthly forecast have been automated within WAFARi.

\section{RESEARCH}

A fundamental part of the service has, and continues to be, the robust science that underpins it. The substantial intellectual input into the service has arisen through relationships with several research providers, including CSIRO and several universities.

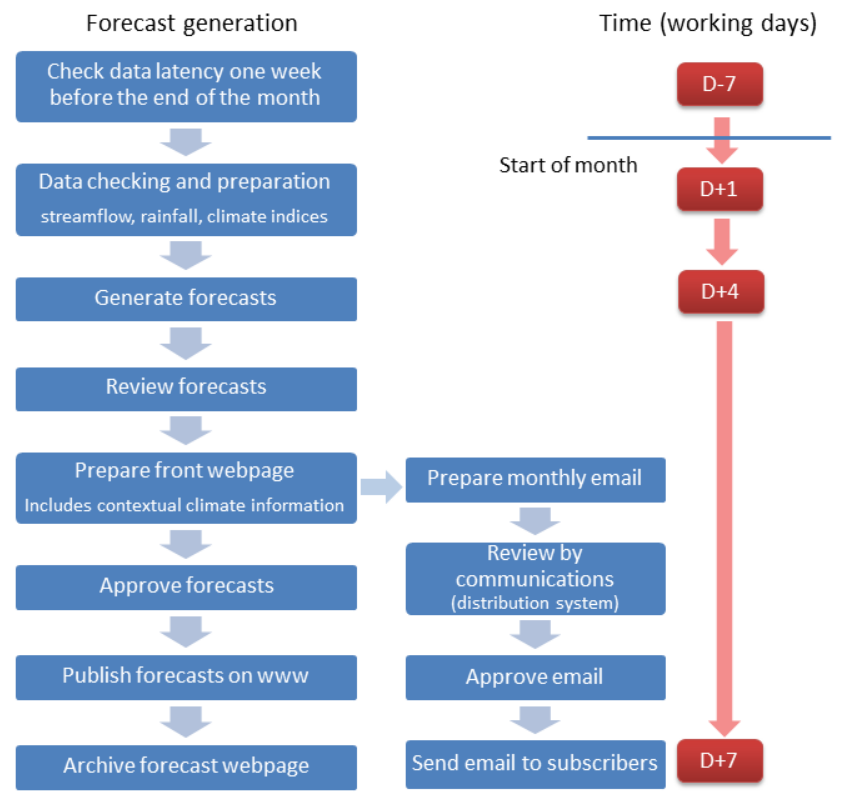

Figure 2. Flow chart showing the major steps in providing the forecasting service each month.

\subsection{WIRADA}

Solid science underpinning the service was ensured through a strong partnership between the Bureau and CSIRO through the Water Information Research and Development Alliance (WIRADA). This close partnership has resulted in many mutual benefits, including increased research impact through direct research and development expertise to focus on the Bureau's requirements for water forecasting, and also by providing a well-defined delivery pathway into Bureau operational services and systems. For example, work is currently underway to bring into operation a quantile model averaging method (Schepen and Wang, 2015), developed by CSIRO, for merging forecasts from the two models to take advantage of the different strengths of the statistical and dynamical approaches.

\subsection{Universities}

Research collaboration with the Universities of Newcastle and Adelaide has led to development of a sophisticated model calibration method known as, the Bayesian Total Error Analysis (BATEA; Kavetski et al., 2006). This method considers uncertainty from different sources including that from errors in data measurement and model structure errors. The Bureau has brought this method into operation, and it is a key component in a fully automated WAFARi system. This allows for a comprehensive treatment of hydrologic uncertainty.

\section{STAKEHOLDER ENGAGEMENT}

As Plummer et al (2009) noted, the ultimate aim of issuing forecast information is for it to result in a change in decisions that lead to improved outcomes. Producing accurate and reliable predictions is a necessary but insufficient requirement on its own to satisfy end users. A consistent theme, right from early inception to the present day, has been involvement of end users in the development and continued refinement of the service. One of the Bureau's roles is to ensure that our seasonal forecast information reaches users as clearly as possible, in forms that are digestible and ultimately enhance decision making. 


\subsection{Initial product and service design}

In the early days, engagement with stakeholders focused on developing user needs, through a variety of activities including planning meetings, targeted workshops, and site visits to better understand each potential user's specific needs. These were then prioritised and published as a communication and adoption strategy. After initial consultation with stakeholders, prototypes of the system and service were quickly developed, and feedback from users was continually invited. The Bureau responded quickly to this feedback, and services and products developed under an iterative process. We found that, once stakeholders were given prototypes, they provided much more specific and detailed feedback on the proposed products. All web pages and products have gone through this type of close review process with internal and external stakeholders.

Workshops and surveys to clearly identify user needs were fundamental to understand how and why the forecasts would be used and to guide development. Involvement of stakeholders at a very early stage was important, because the forecasts are probabilistic and inherently uncertain. Many end users prefer more deterministic and relatively certain forecasts. It was important to communicate this clearly and to manage expectations. Feedback from stakeholders led to the service incorporating different product types - ones that are probabilistic (e.g. Figure 1a), and others that are more deterministic in nature.

Consideration was also given to existing Bureau groups that had themselves established operational services in consultation with stakeholders. In particular, previous experience gained through developing the flood forecasting and warning service, and the seasonal climate outlook service, provided a valuable lead in the development of the seasonal streamflow forecasting service.

Rapid prototype and testing in response to stakeholder interaction was possible by combining several mature $3^{\text {rd }}$ party open source libraries. By using both Python and Fortran programming languages, we could utilise many features of Python for the modelling service, without sacrificing overall computing performance.

\subsection{Web survey}

A web based survey was conducted in December 2013 to gauge performance against several indicators related to user satisfaction and adoption of the service (Wilson et al., 2013). Subscribers of the monthly service email were invited to complete an online survey. In addition, we reviewed visitor traffic to the public seasonal streamflow forecasts website. Valuable suggestions about ways to improve the seasonal streamflow forecasts and the website were received in the survey.

Eighty-seven stakeholders completed the survey, $88 \%$ of which expressed satisfaction with the existing service. This exceeded a service target of $85 \%$, an indication it was meeting performance targets relating to user satisfaction and adoption. The survey showed that end users work in a range of organisation types including government and industry through to the general public, and include sectors in agriculture, engineering, mining and resources.

Importantly, there were examples of users who changed their decisions based on the forecasts and a good outcome was achieved. The survey also highlighted that $9 \%$ of respondents directly use the forecast values in their decision-making, and a further $48 \%$ use the forecasts to support decisions in relation to water allocation outlooks, determining water restrictions, scheduling irrigation, water markets, managing river operations and scheduling environmental watering.

\subsection{Targeted workshops and meetings}

Over recent years, the focus of these gatherings has been to identify new locations for the service. This has been particularly true for Western Australia and Tasmania, where there are regional characteristics that result in a reduction in forecast performance at some locations. Across western Tasmania, this results in part from the combination of relatively high rainfalls and shallow soils, meaning that catchments show less persistence than in other areas. On the other hand, in Western Australia, the transition from dry to wet periods can occur suddenly, and again, a lack of persistence occurs during this time. These are complex issues that require focused discussions.

Close stakeholder meetings and communication was an important part of discussing the issues and limitations, and to identify those locations where forecasts would have the greatest benefit to potential end users. Forecasting process is complex and time consuming, and is therefore not possible to provide forecasts at all locations. Stakeholder engagement has been vital to identify strategically important forecast locations. The expansion that has occurred in 2014-2015, particularly in Tasmania and Western Australia, has been achieved through targeted discussion with key stakeholders in those regions. Model performance varies by 
location and by season. Involvement of stakeholders in site selection is an important part of identifying locations where forecasts are likely to offer most value. Being transparent about limitations of forecast performance is vital.

The Bureau also engages with key external stakeholders through the National Climate and Water Briefings, held towards the end of each month in Canberra. At these briefings, climate and water observations, current conditions, and seasonal outlooks are presented, in a context that is easy to understand.

The streamflow forecasts are also used for contextual information for the Bureau's monthly climate outlooks. They are used in background documents, and provide forecasters and other Bureau staff who deal with media a clear and concise summary of the outlooks. The national map is included to provide climatologists and forecasters with a clear national overview to put climate and water into perspective.

\subsection{Case studies}

One powerful way to demonstrate value of the forecasting service, and to encourage more users to include it in their decision making, is to develop case studies with individual users that describe how they use the forecasts in decision making. The studies describe how forecasts provide more accurate information relative to using historical data alone.

These case studies usually take the form of a two-page document, and raise the profile of the user by showing how they use the best available information to inform decision making. The case studies demonstrate how they are used, so stakeholders are exposed to these details as well. We currently have one completed case study that describes how Icon Water (ACT) used the forecasts to inform their decision to correctly remove water restrictions at the end of the Millennium drought. The intention is that case studies such as this one will help increase the level of adoption of the forecasts by increasing the number of users who directly use the forecasts in their decision making.

\subsection{Videos and social media}

To engage external stakeholders, the Bureau has more recently embraced the use of video and social media, including Facebook, twitter and Youtube, in addition to its usual delivery channel via the standard Bureau web pages.

In 2014, the Bureau developed a monthly video that describes recent conditions, and then presents seasonal climate and water outlooks as well as contextual information. These videos provide opportunities for the Bureau to bring its diverse areas of expertise, including climate and water monitoring and prediction, all into one location. It also allows the Bureau to address the shift in the way in which an increasing number of people prefer to consume information through videos.

The four minute videos are produced, generally in the last week of the month, and released to the web, Facebook, YouTube and to ABC-TV Landline. The streamflow forecasts are now exposed to over 500,000 viewers, and a much broader audience than before. The Bureau has also produced a range of educational videos (for seasonal streamflow forecasting, among others), to complement the monthly videos.

\section{SERVICE DELIVERY}

The third important ingredient is having a robust system and process in place to deliver the forecasts each month.

\subsection{System}

The Water Availability Forecasts of Australian Rivers (WAFARi) modelling system is used to support timely and reliable delivery of seasonal streamflow forecasts (Shin et al. 2011). The system was built by integrating model kernels developed by research partners with Python solutions. Currently, the system integrates kernels for BJP, BATEA and rainfall-runoff models.

The system features a flexible and extendible modular structure, self-descriptive data files with fully annotated metadata, tools for highly tailored visual products, and a scriptable interface for the entire system. Some of the tools are designed to exploit the parallel computing power of the large Bureau cluster to speed up the computationally intensive operations of BJP and dynamic models with an increasing number of forecast locations. 


\subsection{Data supply}

A vital requirement of the service is availability of near real time observed daily streamflow data at each forecast location. Therefore, a vital component of the service is to have an efficient data delivery system in place. This data is obtained from the Australian Water Resources Information System (AWRIS) - a powerful information system capable of receiving, standardising, organising and interpreting water data from across the Australia. The service requires access to data with no more than three day latency. This is to provide sufficient time for data checking and quality control and then forecast generation before the seventh day of the month.

Data checking remains the most time consuming process for the service. Frequent handling of large datasets is prone to error if clear guidelines and processes are not in place to reduce the risk of this. With the rapid expansion of locations from 74 to nearly 200 , not only did the workload increase in terms of data checking, but so too did the risk of not having the observed data for all locations available on time to issue the forecasts. A service level agreement developed in 2013 was revised to include an escalation protocol that describes the process to follow if data is unavailable. It also includes a list of locations covered by the agreement, which is updated with additional locations as they are included in the service.

Under the agreement, the forecast team monitors data supply and quality one week before the end of the month, to provide early warning for serious data latency issues so that the data supply team can act on this. The data supply team then undertakes investigations into data latency issues, and liaises with data providers when required, to provide the best chance that data is available on time for each location. The agreement has resulted in the data team providing a valuable link between data suppliers across Australia and the forecasting service. To date the agreement has worked very well to minimize the risk of not having the required streamflow observations.

In addition to the streamflow data feed from AWRIS, estimates of total monthly inflow volumes (generally for water storages) are provided by individual water managers via email in the first five working days of the month. These water managers include Icon water, Murray-darling Basin Authority (MDBA), GoulburnMurray Water, Melbourne Water, WaterNSW and Water Corporation (in Western Australia).

Several climate indices are obtained from the National Oceanic and Atmospheric Administration (NOAA) website which are generally available during the first five working days of each month. Some climate indices are derived from sea surface temperature data and are also available through NOAA.

\subsection{Staff training and competency}

With more locations and an increased workload, particularly related to manual tasks of data checking, it is important to provide depth and flexibility among service staff in the case of planned or unplanned absences. Any new team members are trained to a required competency standard in tasks associated with issuing the forecasts, from data ingestion and checking, to forecast generation, to generating additional products and updating web page and email text. Each team member is rostered through the various forecast tasks so that skills in each remain current.

\section{FUTURE PLANS}

One key aspect of future plans is to increase the number of locations, particularly in regions that are not currently included in the service. We envisage the service including between 300 and 400 locations as shown in Figure 3.

Plans are underway to develop forecasts for individual months (rather than an aggregated total volume for three months), and to extend the forecast period beyond the current three months. Development of a forecast model for extending streamflow forecasts out beyond three months and providing forecasts in monthly volumes is a major undertaking through WIRADA research.

Currently, the Bureau operates the Predictive Ocean Atmosphere Model for Australia (POAMA) for seasonal climate forecasting. Outputs from the POAMA model are post-processed and fed into streamflow forecasting models.

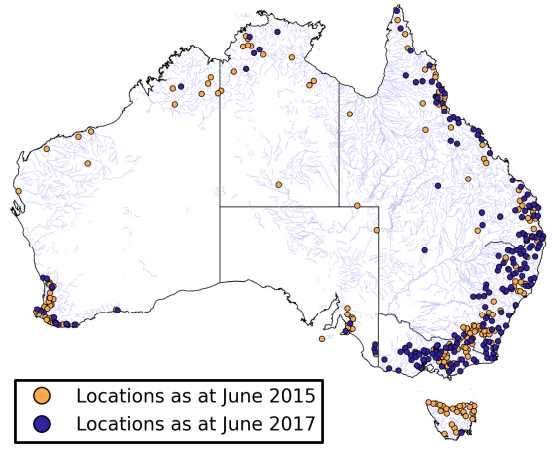

Figure 3. Current (200; orange) and potential future (200, purple) locations in the seasonal streamflow forecasting service. 
Feikema et al., A Seasonal streamflow forecasting service across Australia

In the next 2-3 years, the Bureau will move to a new and improved climate forecasting model, ACCESS-S. Consequently, a high priority for WIRADA research will be providing research support to the streamflow forecasting service in making its transition to ACCESS-S.

\section{CONCLUSIONS}

In summary, the key ingredients for the successful development and delivery of the current seasonal streamflow forecasting service across Australia are;

- Strong scientific basis and foundations for the modelling and forecasting approach;

- Deep and continued communication and collaboration with end users during product development and forecast use; and,

- Robust systems that allow for timely and efficient processing of large volumes of data.

These can only be achieved with meaningful and sustained relationships both within the Bureau, and with the stakeholders whose use of the forecasts will ultimately lead to better informed decisions.

\section{ACKNOWLEDGMENTS}

Development and delivery of the Seasonal Streamflow Forecasting service is funded through the Water Information Program of the Australian Government with guidance from Dasarath Jayasuriya, Graham Hawke and Rob Vertessy. We acknowledge those who have and continue to contribute to the service. These include Neil Plummer, Jeff Perkins, Richard Laugesen, Terence Chia (Bureau of Meteorology), QJ Wang, David Robertson, Andrew Schepen, James Bennett, Quanxi Shao, Ming Li, Enli Wang and Hongxing Zheng (CSIRO), George Kuczera (University of Newcastle), Mark Thyer, Dmitri Kavetski (University of Adelaide). Neville Garland and David Dreverman have also provided critical support. Finally, we thank the many stakeholders who have, and continue to, engage with us to further improve the service.

\section{REFERENCES}

Bureau of Meteorology (BoM; 2010), Seasonal Streamflow Forecasts, Australian Government http://www.bom.gov.au/water/ssf

Kavetski, D., Kuczera, G. and Franks, S.W. (2006), Bayesian Analysis of Input Uncertainty in Hydrological Modeling: 1. Theory, Water Resources Research, 42(3), W03407.

Perrin, C., Michel, C., and Andréassian, V. (2003), Improvement of a parsimonious model for streamflow simulation. Journal of Hydrology, 279, 275-289.

Plummer, N., Tuteja, N.K., Wang, Q.J., Wang, E., Robertson, D., Zhou, S., (2009). A Seasonal Water Availability Prediction Service: Opportunities and Challenges. 18th World IMACS / MODSIM Congress, Cairns, 13-17.

Schepen, A. and Wang, Q.J., (2015), Model Averaging Methods to Merge Operational Statistical and Dynamic Seasonal Streamflow Forecasts in Australia, Water Resources Research, 51(3), 1797-1812.

Shin, D., Schepen A., Peatey T., Zhou S., MacDonald A., Chia T., Perkins J., and Plummer N. (2011), WAFARi: A new modelling system for seasonal streamflow forecasting service of the Bureau of Meteorology, Australia, MODSIM 2011, Perth. pp. 2374-2380.

Tuteja, N.K., (2015), Reliable water availability forecasts for Australia. Water Journal, (April), 70-72.

Vertessy, R.A., (2013), Water information services for Australians, Australian Journal of Water Resources, 16(2), 91-106.

Wang, Q.J., Robertson, D.E. and Chiew, F.H.S., (2009), A Bayesian joint probability modeling approach for seasonal forecasting of streamflows at multiple sites. Water Resources Research, 45, W05407.

Wang, Q.J., and Robertson D.E. (2011), Multisite probabilistic forecasting of seasonal flows for streams with zero value occurrences. Water Resources Research, 47, W02546.

Wilson,T., Feikema.,P., and Ridout, J., (2014), 2013 User feedback on the Seasonal Streamflow Forecasts Service. Internal report, Bureau of Meteorology, pp. 38. 